\title{
Formation and Fluorimetric Characterization of Micelles in a Micro-flow Through System with Static Micro Mixer
}

\author{
Michael Schuch, G. Alexander Gross and J. Michael Köhler * \\ Institute for Micro and Nanotechnologies, Institute for Physics, Techn. Univ. Ilmenau, 98684 Ilmenau, \\ Germany
}

* Author to whom correspondence should be addressed. E-mail: michael.koehler@tu-ilmenau.de Received: 9 October 2007 / Accepted: 22 October 2007 / Published: 30 October 2007

\begin{abstract}
The formation and behaviour of micelles of sodium dodecylsulfate in water by use of a static micro mixer were studied. Trisbipyridylruthenium(II) was applied as indicator dye, 9-methylanthracene was used for fluorescence quenching. All experiments were carried out by a micro fluid arrangement with three syringe pumps, a $2+1$ two-step static micro mixer (IPHT Jena) and a on-line micro fluorimetry including a luminescence diode for excitation, a blue glass filter (BG 7, Linos), two edge filters (RG 630, Linos) and a photo counting module (MP 900, Perkin Elmer). It was possible to measure the fluorescence inside the PTFE tube (inner diameter $0.5 \mathrm{~mm}$ ) directly. A linear dependence of fluorescence intensity from dye concentration was observed in absence of quencher and surfactant as expected. An aggregation number of about 62 was found in the flow rate range between 300 and $800 \mu \mathrm{L} / \mathrm{min}$. The fluorescence intensity increases slightly, but significant with increasing flow rate, if no quencher is present. In the presence of quencher, the fluorescence intensity decreases with decreasing surfactant concentration and with enhanced flow rate. The strength of the flow rate effect on the fluorescence increases with decreasing surfactant concentration. The size of micelles was determined in micro channels by the micro fluorimetric method in analogy to the conventional system. The micelles extract the quencher from the solution and lower, this way, the quenching effect. The size of micelles was estimated and it could be shown, that the flow rate has only low effect on the aggregation number at the investigated flow rates. The effect of flow rate and surfactant concentration on the fluorescence in the presence of quencher was interpreted as a shift in the micelle concentration due to the shear forces. It is expected, that the fluorescence intensity is lowered, if more quencher molecules are molecular disperse
\end{abstract}


distributed inside the solution. Obviously, the lowered fluorescence intensity at higher flow rates suggests a reduction of the micelle density causing an increase of quencher concentration outside the micelles.

Keywords: microreaction technology, micelles, aggregation number, shear stress, laminar flow, fluorescence quenching

\section{Introduction}

The first micro reactors were mainly constructed for the processing of homogenous phases. The handling of homogenous phases in microreactors is less demanding than that of heterogeneous systems in micro reactors. Although heterogenous systems are of great importance for many chemical and biological applications, they are avoided frequently, if micro reactors are used. The generation or introduction of heterogenous systems in micro fluidic systems is accompanied with disturbances in many cases. Such perturbations include precipitations, increasing flow resistance, sedimentation, particle adsorption at the wall surfaces and blocking. Gas bubbles cause elastic answering behaviour of the micro fluidic system against pressure changes by the compression and expansion of the gas.

Despite these problems, the application of micro reactors for heterogenous chemical systems attracted more and more interest during the last years. Liquid/liquid two phase systems and liquid/liquid gaseous multi phase systems were introduced in order to generate ideal plug flow behaviour in micro fluidic arrangements for fast serial processing [1-8]. Liquid/liquid heterogenous systems and particular micro segmented-flow systems are of interest for chemical [9-15] as well as for biological applications [16-18]. Beside liquid interfaces, solids can also be handled in micro reactors. It was shown, that dielectric micro and nanoparticles can be generated in micro flow-through systems [19-22]. Metal nanoparticles are of particular interest concerning labeling of biomolecules and biochips [23-24]. The formation of metal nanoparticles and the growth of metal nanoseeds by reduction of metal salt solutions in micro reactors succeeded, too [25-27]. Micro mixers were used for the synthesis of polymers by emulsion polymerization and yield polymer nano particles [28, 29].

The control of interface states is a critical parameter for a successful handling of heterogenous systems in micro reactors. The properties of solid interfaces can be modified by deposition of thin organic or inorganic films as well as by the immobilization of molecules. Liquid surfaces and liquid/liquid interfaces can easily be modified by the introduction of surfactants. Surfactants stabilize the liquid droplets in emulsions and can also act as stabilizers for suspensions and colloidal solutions. The addition of surfactants influences the formation of nano particles [30, 31] and can be used for the generation of metal nanorods in a micro fluid synthesis [32].

Surfactants can form micelles as a particular type of nanoscale objects above a characteristic concentration, the critical micelle concentration cmc [33]. Micelles are supramolecular objects forming by self assembling of amphiphilic molecules. The single micelles are in a thermodynamic equilibrium with surfactant molecules molecular disperse distributed in solution. The exchange rates are high. Thus, micelles must be understood as highly dynamical objects [34]. The formation of micelles is 
expected in all cases of higher surfactant concentrations in micro reactors, and, therefore, it is of great importance for all heterogenous systems manipulated in micro reactors under addition of surfactants. Although, the application of surfactants is of great interest for micro fluidics, low attention was paid to the behavior of micelles under micro fluidic conditions. In this work, the formation of micelles in a micro fluidic system was investigated by means of a fluorimetric method. Shear stress and the influence of flow rate on the optical response related to the micellar state were studied.

\section{Experimental}

\subsection{Chemicals and micelle formation}

All used chemicals were pA. graded. Sodium dodecylsulfate (SDS) was applied as model substance, because it represents a frequently applied anionic surfactant. It is known, that micelles of SDS in water possess an electrical excess charge. For the ratio between positive counter ions and the number of SDS molecules inside a micelle, numbers between 0.46 and 0.86 were reported [35]. This value depends on the size and chemical structure of the charged or polar head group and the length and mobility of the hydrophobic tail group and, in particular on the properties of the solvent and the kind and concentration of other ions contained. The excess charge of the micelles is mainly responsible for the repulsion between the molecular ensembles and therefore for the thermodynamical stabilization of the whole system.

Ionic surfactants like SDS preferably form smaller micelles. The aggregation number is normally in the range between 10 and 100, whereas non-ionic surfactants can form micelles of about $10^{4}$ molecules. Mean aggregation numbers between 60 and 83 are reported for SDS in water, for example $[35,36]$.

\subsection{Micro fluidic arrangement}

It was the aim to characterize the micellar solution inside a tube capillary immediately after mixing of the components. Therefore, a two step static micro mixer was applied. Static micro mixers are widely accepted $[37,38]$. The applied mixer is constructed based on a fluidic lamination principle based on several split and recombine units. The channel structures are prepared photo lithographically using Si and glass substrates and applying wet etching technology. A three chip sandwich technology including two glass chips at the bottom and the top and a silicon chip between them was applied in order to get a good splitting and reshaping behavior at the fluid stream. The construction and preparation technology of the micro mixer class was described previously [39].

Here, a two step mixer was applied: Two liquids were brought together at first, and a third liquid was added by in a second mixing step. Syringe pumps were used for fluidic actuation.

The outlet of the mixer was directly connected with the PTFE tube, in which the characterization occurred. The glass fibers of the measurement arrangement were placed directly behind the outlet of the mixer (Figure 1). 


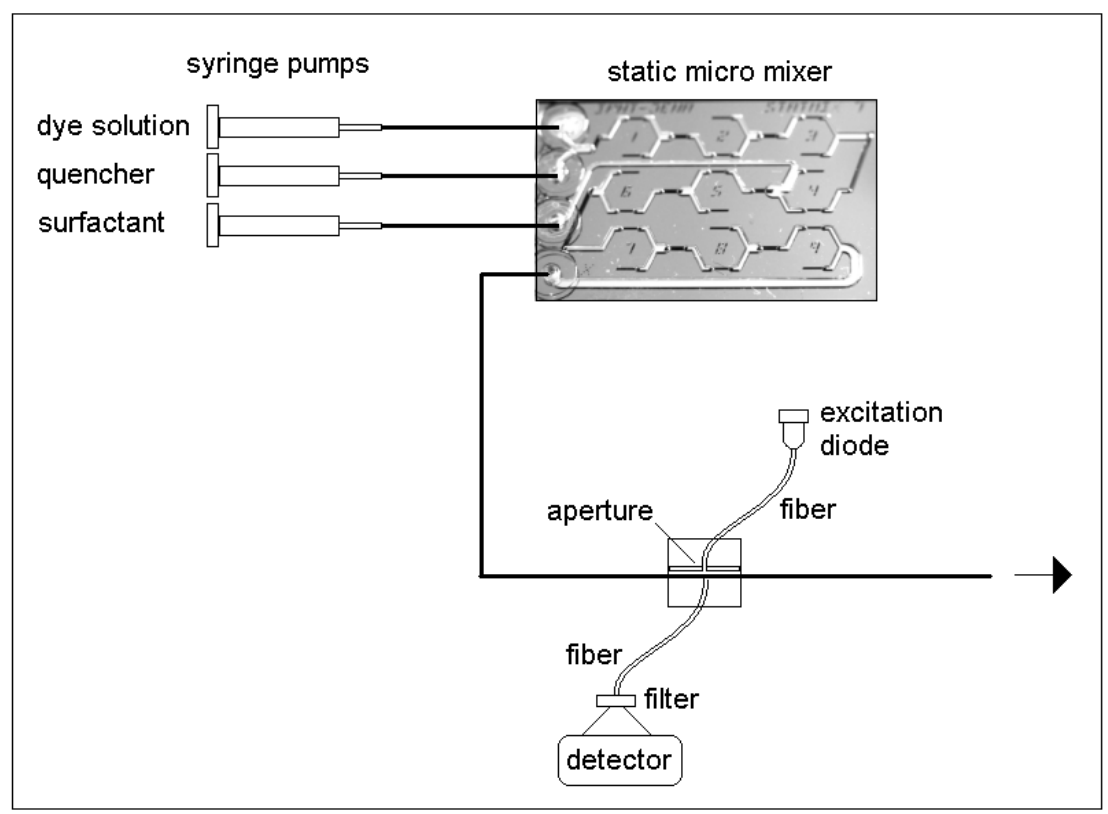

Figure 1. Experimental arrangement for formation and characterization of micelles in a microfluidic system.

\subsection{Measurement principle}

A fast working non-invasive method for the in-situ characterization of the micellar state was needed for the measurement of micelles under micro fluidic conditions. Osmometry was regarded as non suited for the microfluidic application. Optical methods were preferred as non-invasive techniques. Light-scattering was excluded due to the low scatter efficiency of the expected micelles.

Fluorimetry with quencher distribution-dependent fluorescence quenching was chosen as a promising method for the in-situ characterization. Therefore, an ionic fluorescence dye and a rather hydrophobic quencher are applied. Both molecular species - dye and quencher - are molecular disperse distributed inside the solution in case of absence of surfactants or at low surfactant concentration, when no micelles are formed. If the surfactant concentration increases and micelles appear, they show a higher affinity with response to the quencher. As result, quencher molecules go into the hydrophobic centre of the micelles and the local quencher concentration outside micelles is lowered. The consequence is an increase of fluorescence quantum yield of the dye. Here, the tris(bipyridyl)ruthenium cation was used as fluorophore and methylanthracene was applied as hydrophobic quencher [40]. The introduction of quencher in the liquid system was realized by dissolution in acetonitril (Neolab-Migge) and subsequent mixing of the acetonitrilic quencher solution with the aqueous solution. The volume ratio of aqueous solution to acetonitril amounted to 500: corresponding to $0.2 \mathrm{Vol} \%$ organic solvent.

The optical measurements were carried out using a blue light emitting diode (DS 25, royal blue, Luxeon, USA) with a wavelength of $455 \mathrm{~nm}$. An optical filter (blue, BG 7, Linos, Germany) was applied in order to suppress a small red light emission from the light source. A photo counting module (MP 900, Perkin-Elmer) was applied in connection with two optical filters (R. 630, Linos) for the fluorescence intensity measurement. The optical measurements occur directly inside the PTFE tube (inner diameter $0.8 \mathrm{~mm}, 0.4 \mathrm{~mm}$ wall thickness) with the streaming liquid. 


\section{Results and Discussion}

\subsection{Reference measurements at static conditions}

At first, the chemical system was tested inside the PTFE tube without fluidic motion after premixing the components by hand outside the microfluidic system. Therefore a series of solutions with the same quencher $\left(10^{-4} \mathrm{~mol} / \mathrm{L}\right)$ and constant dye concentration was characterized in dependence on the concentration of surfactant (SDS). The premixed solution was introduced into a syringe pump. The fluorescence measurements were carried out after the complete substitution of water inside the PTFE tube by the process mixture.

The SDS concentration was varied between 20 and $50 \mathrm{mmol} / \mathrm{L}$. As expected, a considerable increase in fluorescence intensity was found with increasing SDS concentration (Figure 2). In the log $\mathrm{I} / \mathrm{c}$ plot $\left(\mathrm{I}_{\mathrm{o}} / \mathrm{I}\right.$ vs concentration of SDS) the linear relation was confirmed. The effect of micelle formation and extraction of quencher from the liquid into the micelles is strong. It results in an increase of fluorescence intensity of a little less than 2 orders of magnitude by a concentration increase of the surfactant by a factor of 2.5 , only. The aggregation number at flow-free conditions can be estimated to about 55 molecules per micelle.

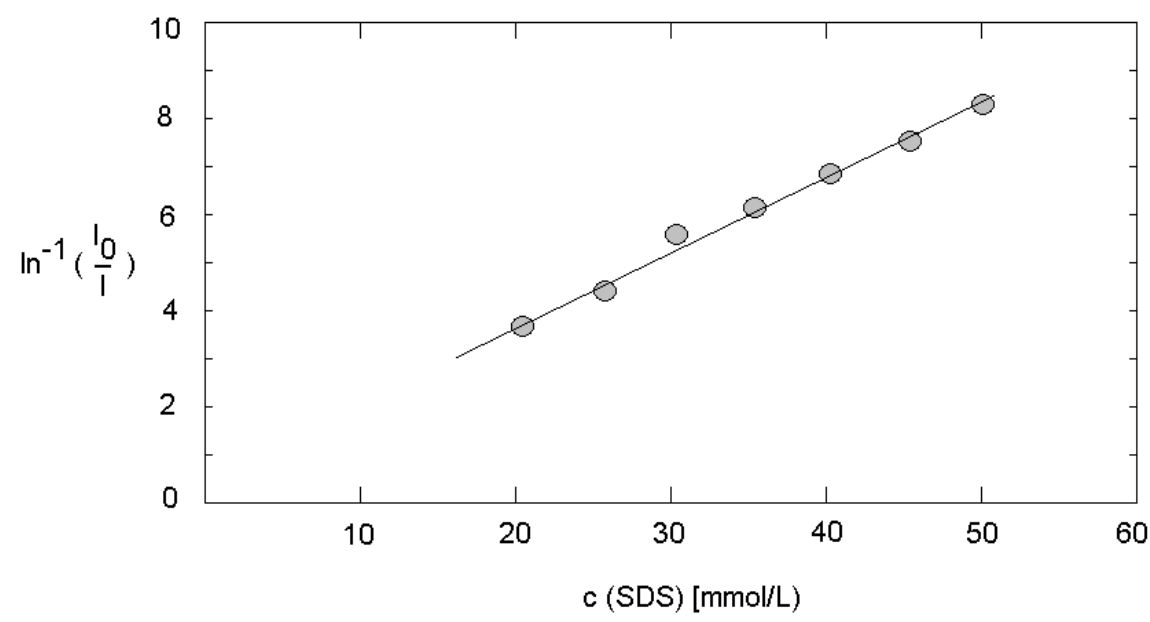

Figure 2. Dependence of fluorescence intensity $\left(\mathrm{Ru}(\text { bipy })_{3}{ }^{2+}\right.$ ) in solutions with constant quencher concentration $(99 \mu \mathrm{mol} / \mathrm{L})$ on surfactant concentration without flow inside PTFE tube.

\subsection{Characterization of micro fluidic arrangement}

The experimental arrangement was fluidically characterized by pumping for the fluorescence dye solution into a carrier stream of pure water. At a flow rate of $250 \mu \mathrm{L} / \mathrm{min}$, the fluorescence intensity increases quickly within the first $60 \mathrm{~s}$ after starting the fluorescence dye stream. After about $250 \mathrm{~s}$ the fluorescence signal came into saturation indicating a stationary state in the fluidic system. The time to saturation is independent on the concentration of fluorescence dye.

The applicability of fluorescence measurements inside PTFE tubing by the above mentioned fiberoptical system as a quantitative method at applied flow was tested by varying the dye concentration at a certain flow rate. Therefore, solutions of tris(bipyridyl)ruthenium with 
concentrations between 2 and $21 \mu \mathrm{mol} / \mathrm{L}$ were pumped through the system. The fluorescence intensities were determined $250 \mathrm{~s}$ after switching on the syringe pump, and the optical signals were averaged over $10 \mathrm{~s}$. In result, a good linear relation between the dye concentration and the measured fluorescence intensity was found (Figure 3).

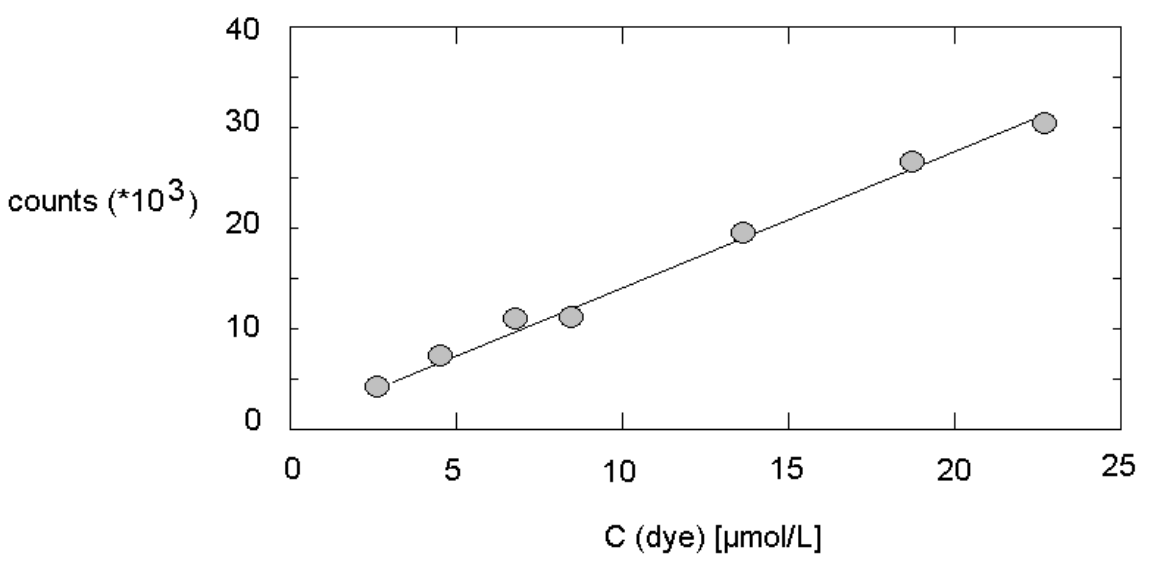

Figure 3. Fluorescence intensity measured inside the PTFE tube in dependence on dye concentration under stationary micro fluidic conditions.

\subsection{Fluorescence intensity and micelle formation under micro fluidic conditions}

Fluorescence measurements in dependence on flow rate showed a slight increase of fluorescence intensity in absence of any quencher if SDS is present. The enhancement of the over-all flow rate from $400 \mu \mathrm{L} / \mathrm{min}$ to $800 \mu \mathrm{L} / \mathrm{min}$ lead to an increase of the intensity of emitted light of $2.5 \%$ in case of solutions containing $27.5 \mathrm{mmol} / \mathrm{L} \mathrm{SDS}$. This observed increase is small, but it is significant (Figure 4). Obviously, the increasing shear stress with increasing flow rate improve the fluorescence quantum yield. But, the increase of fluorescence with flow rate is weaker than linear.

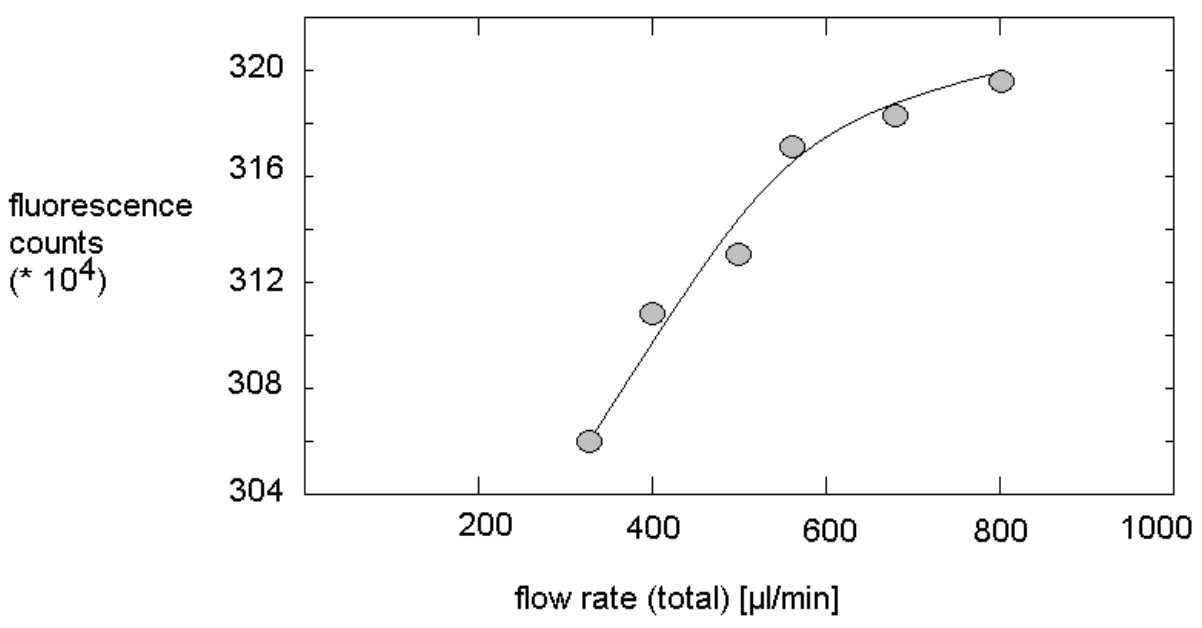

Figure 4. Increase of fluorescence intensity in dependence on flow rate in dye solutions containing $27.5 \mathrm{mmol} / \mathrm{L}$ SDS but no quencher (constant dye concentration). 
The function of fluorescence increase with increasing flow rate is dependent on SDS concentration. The enhancement of fluorescence intensity with increasing flow rate increases with increasing SDS concentration. This fact supports the assumption, that the molecular self organization, the structuring inside the liquid and the influence of the shear stress at laminar flow conditions is responsible for the fluorescence increase. It is to assume, that the formation of micellar structures lowers slightly the molecular mobility of the dye and the laminar flow causes a certain enhancement of regularity inside the liquid.

3.4. Fluorescence behavior in presence of quencher and determination of aggregation number at micro fluidic conditions

The strong effect of SDS on the fluorescence intensity in case of presence of a hydrophobic quencher was confirmed at micro fluidic conditions. The enhancement of SDS concentration from 20 to $30 \mathrm{mmol} / \mathrm{L}$ in experiments with a total flow rate of $600 \mu \mathrm{L} / \mathrm{min}$ causes an increase of fluorescence intensity up to about $500 \%$. A linear correlation was found in the dependence of $1 / \log (\mathrm{I} / \mathrm{Io})$ versus the surfactant concentration (Figure 5). The slope of the plot allows the estimation of the aggregation number in the dynamic system. With $62+/-3$, this number deviates only slightly from the value under static conditions. The investigations over a flow rate range from 300 up to $800 \mu \mathrm{L} / \mathrm{min}$ confirmed this finding: the aggregation number is nearly independent on flow rate, in this flow rate range.

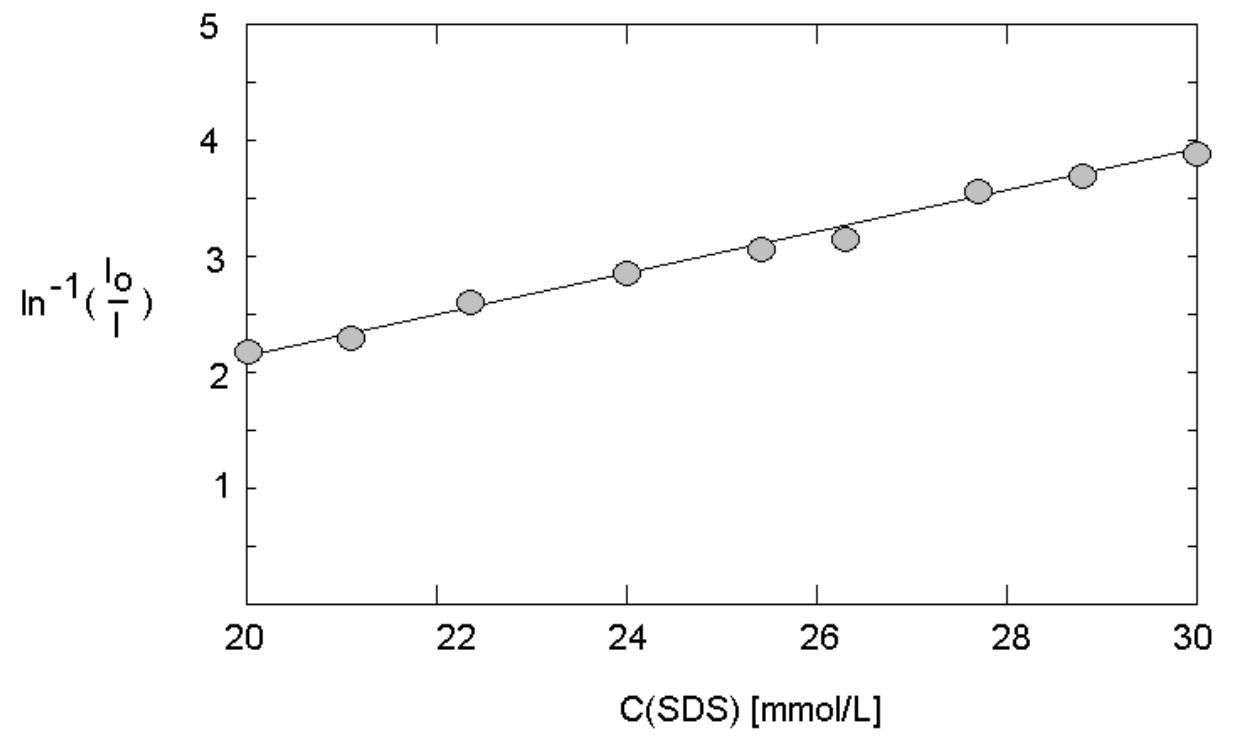

Figure 5. Dependence of fluorescence intensity on the surfactant concentration at micro fluidic conditions (flow rate: $600 \mu \mathrm{L} / \mathrm{min}$; quencher concentration: $10^{-4} \mathrm{~mol} / \mathrm{L}$; dye concentration: $10^{-4} \mathrm{~mol} / \mathrm{L}$ ).

In contrast, a certain effect of decreasing micelle density with increasing flow rate can be concluded from the flow-rate-dependent measurements. This observation corresponds to a slight increase of the concentration of the free surfactant molecules. It seems, that the shear stress is not effecting the size of micelles, but causes a certain shift in the ratio of micelles and free surfactant molecules. Probably, the cmc is also enhanced in micro fluidic systems. This interpretation agrees well with the observation of a slight, but significant reduction of fluorescence intensity with increasing flow rate at different SDS concentration. The effect of flow rate on fluorescence increases with decreasing SDS content 
(Figure 6). This effect can be explained by the equlibirum of distribution of quencher molecules between the micelles and the solution. A decreasing density of micelles causes an increase of concentration of free quencher molecules.

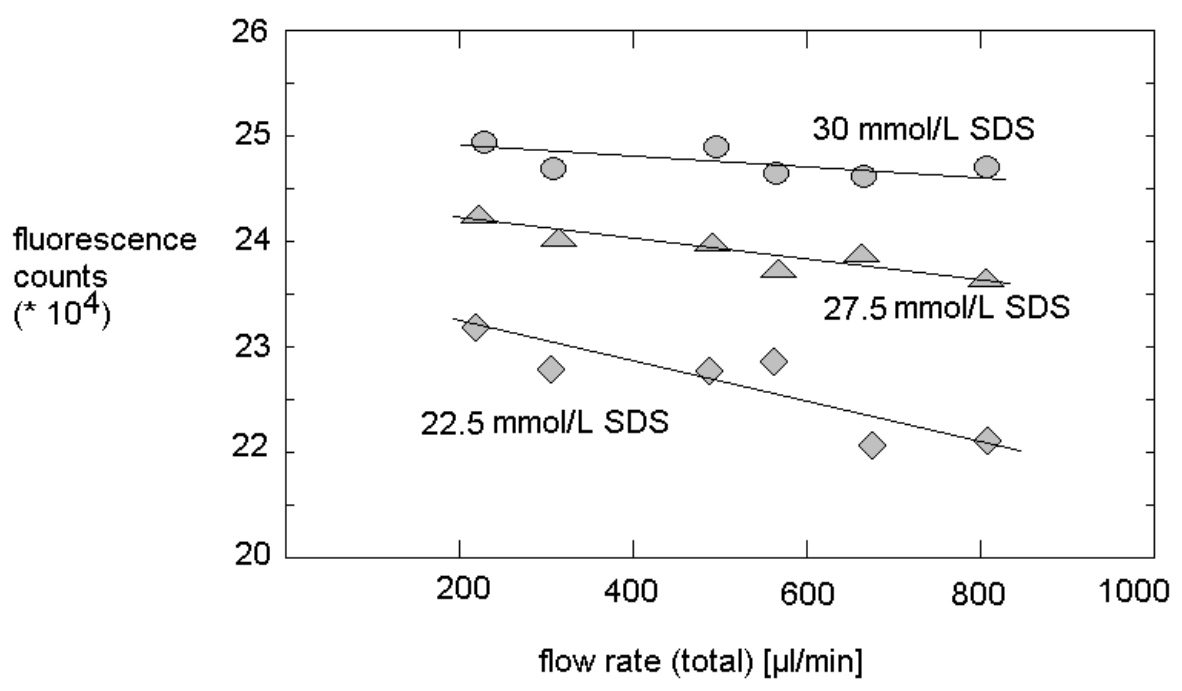

Figure 6. Flow-induced reduction of fluorescence intensity for different SDS concentrations.

\section{Conclusions}

Micellar solutions can be characterized in micro fluidic systems by use of fluorimetric measurements. The determination of fluorescence intensity in the presence of a hydrophobic quencher was successful applied for the determination of the dependence of micelle formation on flow rate and surfactant concentration.

It was found, that the aggregation number can be determined rather precisely with this method.

For the applied microsystem and at medium volume flow rates the value found for the aggregation number was in the same range as at static conditions. Despite this finding, enhanced flow rates cause a decrease in fluorescence intensity. This effect is stronger for smaller surfactant concentrations. This leads to the conclusion, that not the size, but the density of micelles is reduced due to shear stress in micro fluidic systems.

The investigations show the importance of fluorimetric in-situ measurements for the monitoring of surfactant-containing solutions in micro reactors and other micro fluidic systems. In future, studies should address the behavior of systems at higher shear stress, for example of other the influence of other surfactants, of lipophilic and macromolecular components.

\section{Acknowledgement}

We thank S. Schneider for the construction of the optical measurement arrangement, J. Albert and the clean room staff of IPHT (Jena) for the design and the preparation of the static mixer and J. Wagner for support and helpful discussions. The financial support of the German Environmental Foundation (DBU) is gratefully acknowledged. 


\section{References and Notes}

1. Burns, J.R.; Ramshaw, C. The intensification of rapid reactions in multiphase systems using slug flow in capillaries . Lab on a Chip 2001, 1, 10-15.

2. Thorsen, T.; Roberts, R.W.; Arnold, F.H.; Quake, S.R. Dynamic Pattern Formation in a VesicleGenerating Microfluidic Device. Phys. Rev. Lett. 2001, 86, 4163- 4166.

3. Nisisako, T.; Torii, T.; Higuchi, T. Chemical reactions in microdroplets by electrostatic manipulation of droplets in liquid media. Lab on a Chip 2002, 2, 19-23.

4. Nisisako, T.; Torii, T.; Higuchi, T. Droplet formation in a microchannel network. Lab on a Chip 2002, 2, 24-26.

5. Link, D.R.; Anna, S.L.; Weitz, D.A.; Stone, H.A. Geometrically Mediated Breakup of Drops in Microfluidic Devices. Phys. Rev. Lett. 2004, 92, 054503

6. Nisisako, T.; Okushima, S.; Torii, T. Controlled formulation of monodisperse double emulsions in a multiple-phase microfluidic system. Soft Matter 2005, 1, 23-27.

7. Köhler, J.M.; Kirner, T. Nanoliter segment formation in micro fluid devices for chemical and biological micro serial flow processes in dependence on flow rate and viscosity. Sensors and Actuators A 2005, 119, 19-27.

8. Balasz, A.C.; Verberg, R.; Pooley, C.M.; Kusenok, O. Modeling the flow of complex fluids through heterogeneous channels. Soft Matter 2005, 1, 44-54.

9. Song, H.; Tice, J.D.; Ismagilov, R.F. A Microfluidic System for Controlling Reaction Networks in Time. Angew. Chem. 2003, 115, 792-796.

10. Ismagilov, R.F. Integrierte Mikrofluidsysteme. Angew. Chem. 2003, 115, 4262-4264

11. Shestopalov, I.; Tice, J.D.; Ismagilov, R.F. Multi-step synthesis of nanoparticles performed on millisecond time scale in a microfluidic droplet-based system. Lab on a Chip, 2004, 4, 316-321.

12. Zheng, B.; Tice, J.D.; Ismagilov, R.F. Formation of Droplets of Alternating Composition in Microfluidic Channels and Applications to Indexing of Concentrations in Droplet-Based Assays. Anal. Chem. 2004, 76, 4977-4982.

13. Köhler, J.M.; Henkel, T.; Grodrian, A.; Kirner, T.; Roth, M.; Martin, K.; Metze, J. Digital reaction technology by micro segmented flow-components, concepts and applications. Chem. Engn. J. 2004, 101, 201-216.

14. Henkel, T.; Bermig, T.; Kielpinski, M.; Grodrian, A.; Metze, J.; Köhler, J.M. Chip modules for generation and manipulation of fluid segments for micro serial flow processes. Chem. Engn. J. 2004, 101, 439-445.

15. Günther, P.M.; Möller, F.; Henkel, T.; Köhler, J.M.; Groß, G.A. Formation of Monomeric and Novolak Azo Dyes in Nanofluid Segments by Use of a Double Injector Chip Reactor. Chem. Eng. Technol. 2005, 28, 520-527.

16. Martin, K.; Henkel, T.; Baier, V.; Grodrian, A.; Schön, T.; Roth, M.; Köhler, J.M.; Metze, J. Generation of larger numbers of separated microbial populations by cultivation in segmented-flow microdevices. Lab on a Chip 2003, 3, 202-207.

17. Grodrian, A.; Metze, J.; Henkel, T.; Martin, K.; Roth, M.; Köhler, J.M. Segmented flow generation by chip reactors for highly parallelized cell cultivation. Biosensors \& Bioelectronics 2004, 19, 1421-1428. 
18. Brösing, A.; Köhler, J.M. Proc. Kolloquium Heiligenstadt 2004, 12, 381.

19. Hessel, V.; Löwe, H. Mikroverfahrenstechnik: Komponenten - Anlagenkonzeption - Anwenderakzeptanz - Teil 1. Chemie Ingenieur Technik 2002, 74, 17-30.

20. Hessel, V.; Löwe, H. Mikroverfahrenstechnik: Komponenten - Anlagenkonzeption - Anwenderakzeptanz - Teil 2. Chemie Ingenieur Technik 2002, 74, 185-207.

21. Jongen, N.; Donnet, M.; Bowen, P.; Lemaître, J.; Hofmann, H.; Schenk, R.; Hofmann, C.; AounHabbache, M.; Guillemet-Fritsch, S.; Sarrias, J.; Rousset, A.; Viviani, M.; Buscaglia, M.T.; Buscaglia, V.; Nanni, P.; Testino, A.; Herguijuela, J.R. Development of a Continuous Segmented Flow Tubular Reactor and the "Scale-out" Concept - In Search of Perfect Powders. Chem. Eng. Technol. 2003, 26, 303-305.

22. Schenk, R.; Hessel, V.; Werner, B.; Ziogas, A.; Hofmann, C.; Donnet, M.; Jongen, N. Micromixers as a tool for powder production. Chem. Eng. Trans. 2002, 1, 909-914.

23. Chan, E.M.; Mathies, R.A.; Alivisatos, A.P. Size-Controlled Growth of CdSe Nanocrystals in Microfluidic Reactors. Nano Letters 2003, 3, 199-201.

24. Fritzsche, W. DNA-gold conjugates for the detection of specific molecular interactions. Rev. Mol. Biotechnol. 2001, 82, 37-46.

25. Wagner, J.; Kirner, T.; Mayer, G.; Albert, J.; Köhler, J.M. Generation of metal nanoparticles in a microchannel reactor. Chem. Eng. J. 2004, 101, 251-260.

26. Wagner, J.; Köhler, J.M. Continuous Synthesis of Gold Nanoparticles in a Microreactor. Nano Letters 2005, 5, 685-691.

27. Köhler, J.M.; Wagner, J.; Albert, J. Formation of isolated and clustered Au nanoparticles in the presence of polyelectrolyte molecules using a flow-through Si chip reactor. J. Mater. Chem. 2005, 15, 1924-1930.

28. Chang, Z.; Liu, G.; Tian, Y.; Zhang, Z. Preparation of micron-size monodisperse poly(vinyl acetate) microspheres with $\gamma$-rays-initiated dispersion polymerization in microreactor. Materials Letters 2004,58, 522-524.

29. Günther, P.M.; Wagner, J.; Groß, G.A.; Köhler, J.M. Proceedings of the 9th Internatl. Conf. on Miniaturized Systems $\mu$-TAS, Boston, Oct 9-13 2005; pp. 918-920.

30. Noorgard, K.; Weygand, M.J.; Kjaer, K.; Brust, M.; Bjornholm, T. Adaptive chemistry of bifunctional gold nanoparticles at the air/water interface. A synchrotron X-ray study of giant amphiphiles. Faraday Discussions 2004, 125, 221-233.

31. Doty, R.C.; Tsikhudo, T.R.; Brust, M.; Fernig, D. Extremely Stable Water-Soluble Ag Nanoparticles. Chemistry of Materials 2005, 17, 4630-4635.

32. Sönnichsen, K. Presented at 3rd Ilmenauer Workshop on Micro Laboratory Techniques, Ilmenau, Germany, 2006.

33. Dörfler, H.-D. Grenzflächen- und Kolloidchemie; Wiley/VCH: Weinheim, 1994.

34. Moroi, Y. Micelles: Theoretical and Applied Aspects; Springer: New York, 1992.

35. Turro, N.; Yekta, A. Luminescent probes for detergent solutions. A simple procedure for determination of the mean aggregation number of micelles. J. Am. Chem. Soc. 1978, 100, 59515952.

36. Quina, F.H.; Nassar, P.M.; Bonilha, J.B.S.; Bales, B.L. Growth of Sodium Dodecyl Sulfate Micelles with Detergent Concentration. J. Phys. Chem. 1995, 99, 17028-17031. 
37. Schwesinger, N.; Frank, T.; Wurmus, H. A modular microfluid system with an integrated micromixer. J. Micromech. Microeng. 1996, 6, 99-102.

38. Hardt, S.; Drese, K.S.; Hessel, V.; Schönfeld, F. Passive micromixers for applications in the microreactor and mTAS fields. Microfluid Nanofluid 2005, 1, 108-118.

39. Kirner, T.; Albert, J.; Günther, M.; Mayer, G.; Reinhäckel, K.; Köhler, J.M. Static micromixers for modular chip reactor arrangements in two-step reactions and photochemical activated processes. Chem. Eng. J. 2004, 101, 65-74.

40. Draeger, Ch. Mesoskopische Mizellen aus amphiphilen Bipyridiyliumkomplexen mit Ruthenmium (II), Osmium (II) und Palladium (II). Ph.D. Thesis, Techn. Univ. Berlin, 2001.

(C) 2007 by MDPI (http://www.mdpi.org). Reproduction is permitted for noncommercial purposes. 